\title{
Sedulur Sikep Samin: antara Pandangan dan Sistem Pengetahuan
}

\author{
Hanifah Hikmawati ${ }^{1}$ \\ ${ }^{1}$ Institut Agama Islam Ngawi \\ I'hanifah_hikmawati@yahoo.com
}

\begin{abstract}
This article discusses the knowledge system that exists in the community, along with Samin's Sikep, which has been reaping the pros and cons of the community. This assessment has become a stigma against Samin's existence from the past until now. This paper is a reflection of the anthropology carried out by researchers in the context of the knowledge system of the Sedulur Sikep Samin Blora community. The formulations of the problems in this journal are a) how Sedulur Sikep Samin builds awareness of the knowledge they have, b) how Sedulur Sikep interprets the principles of life in everyday life, c) how Sedulur Sikep builds the symbol of knowledge it has. The method used in this research is descriptive qualitative, with the results that describe the knowledge system assumptions of the Sedulur Sikep Samin Blora community to become the identity and symbol of the community itself as a knowledge-based society and a paradoxical, dynamic journey "to the truth", and multidimensional.
\end{abstract}

Key Word: Knowledge System, Samin, Sedulur Sikep

\begin{abstract}
Abstrak
Artikel ini membahas tentang sistem pengetahuan yang ada pada masyarakat sedulur sikep Samin yang selama ini menuai penilaian pro dan kontra dari masyarakat. Penilaian tersebut telah menjadi stigma terhadap keberadaan eksistensi Samin dari dulu hingga sekarang. Tulisan ini merupakan refleksi antropologi yang dilakukan peneliti dalam konteks sistem pengetahuan masyarakat Sedulur Sikep Samin Blora. Rumusan masalah pada jurnal ini, yaitu a) bagaimana Sedulur Sikep Samin membangun kesadaran atas pengetahuan yang dimiliki, b) bagaimana Sedulur Sikep memaknai asas-asas hidup dalam kehidupan sehari-hari, c) bagaimana Sedulur Sikep membangun simbol pengetahuan yang dimiliki. Metode yang digunakan dalam penelitian ini adalah kualitatif deskriptif, dengan hasil yang memaparkan asumsiasumsi sistem pengetahuan yang dimiliki masyarakat Sedulur Sikep Samin Blora menjadi identitas dan simbol dari masyarakat itu sendiri sebagai masyarakat yang berbasis pengetahuan dan perjalanan "menuju kebenaran" yang bersifat paradoksal, dinamis, dan multidimensional.
\end{abstract}

Kata Kunci: Samin, Sedulur Sikep, Sistem Pengetahuan

\section{Pendahuluan}

Dewasa ini, masyarakat telah berubah sedemikian rupa, yang selayaknya disadari dan ditanggapi dalam kerja lapangan para antropolog. Perubahan yang disebabkan oleh berbagai kekuatan, baik dari dalam maupun dari luar, telah menyebabkan apa yang dikatakan masyarakat dan kebudayaan itu 
Sedulur Sikep Samin: antara Pandangan dan Sistem Pengetahuan

sudah berbeda. ${ }^{1}$ Dalam melihat persamaan dan perbedaan, melihat bagaimana hal-ihwal saling berkaitan, terasa akrab dengan analogi. ${ }^{2}$ Kemudian muncul pemikiran kritis terhadap perbedaan yang ada tersebut untuk dikaji lebih mendalam dan menegaskan kembali prinsipprinsip dan memandang teori kebudayaan sebagai hubungan antar unsur-unsur dalam kehidupan sehari-hari. Unsur-unsur dalam kehidupan tersebut ialah segala yang mencakup aspek yang ada dalam masyarakat, termasuk unsur-unsur kehidupan masyarakat Sedulur Sikep Samin Blora.

Melihat kenyataan bahwa masyarakat Indonesia sangat heterogen, sudah tentu tidak mudah untuk menciptakan kondisi yang selaras dengan tujuan pembangunan nasional. Ada kemungkinan karena mereka dapat menerima pembaharuan atau modernisasi, baik yang berasal dari program-program pembangunan maupun yang diperoleh melalui arus informasi akibat desakan globalisasi yang terjadi pada saat ini. Salah satu bentuk unsur kebudayaan yang eksis sampai saat ini adalah ajaran-ajaran, pesan perilaku dan tradisi sebagai sistem pengetahuan yang berkembang pada masanya untuk dijadikan bahan renungan dan pedoman bagi generasi sekarang. Terlebih ketika masyarakat tersebut masih mengimplementasikan pesan atau

1 Irwan Abdullah, Konstruksi dan reproduksi kebudayaan (Yogyakarta: Pustaka Pelajar, 2006), 15.

2 Y Wibowo, "Sastra Dan Peta Yang (Tak) Usai Terbaca," accessed November 29, 2020, http://sastra- amanat dari leluhur yang menjadi teladan terhadap kehidupan sosial masyarakat kini.

Ajaran-ajaran dan sistem pengetahuan yang berkembang di masyarakat Sedulur Sikep Samin merupakan bagian dari kearifan lokal yang menjadi ideologi dan pembelajaran atas resolusi efektif bagi kurun zaman dan masa ke masa. Sistem pengetahuan lokal tersebut adalah pengetahuan yang khas milik suatu masyarakat atau budaya tertentu, dalam hal ini ialah masyarakat sedulur sikep yang telah berkembang lama, sebagai hasil dari proses hubungan timbal balik antara masyarakat dengan lingkungannya.

Orang memandang Samin dengan penilaian yang berbeda-beda, ada yang menilai baik dan ada yang salah mempersepsikannya. Mulai dari anggapan bahwa gerakan masyarakat Samin sebagai simbol perlawanan terhadap kekuasaan kolonial Belanda hingga saat ini, sampai anggapan bahwa masyarakat Samin adalah kumpulan orang-orang tak beragama, aneh dan terbelakang. Samin oleh sebagian besar orang memang lebih sering dipandang dengan kacamata buram atau pandangan yang negatif. Mereka identik dengan segolongan masyarakat yang tidak kooperatif, tidak mau membayar pajak, suka membangkang dan suka menentang. Saminisme sebenarnya

indonesia.com/2008/08/sastra-dan-peta-yang-tak-usaiterbaca/. 
merupakan sebuah paham dan sejarah melainkan mencakup fenomena yang tidak perlawanan terhadap kekuasaan kolonial lain daripada persepsi, pemikiran, kemauan, Belanda yang telah diubah menjadi deskripsi dan keyakinan subjek tentang sesuatu di luar kebudayaan.

Stigma-stigma ini yang mendorong penulis untuk mengkaji lebih lanjut tentang eksistensi Sedulur Sikep Samin atas pengetahuan-pengetahuan yang dimiliki. Kajian ini sekaligus sebagai wawasan agar masyarakat lebih mengetahhui bagaimana Sedulur Sikep Samin berperilaku, lalu stigmastigma negatif yang berkembang dapat ditekan.

\section{Metode Penelitian}

Penelitian ini berada pada bidang ilmu kajian budaya yang tidak bebas nilai. Metode penelitian yang digunakan kajian budaya menggunakan metode penelitian kualitatif dengan pendekatan fenomenologi. Kajian budaya berusaha melangkah lebih jauh dengan memanfaatkan kebudayaan sebagai arena pertarungan ideologis, sehingga budaya bukan semata-mata refleksi sistem ekonomi, tetapi beroperasi secara independen. ${ }^{3}$ Fenomenologi dapat memaknai mencakup berbagai metodologi sebagaimana Edmund Husserl telah mengemukakan bahwa objek ilmu itu tidak terbatas pada yang empirik,

\footnotetext{
${ }^{3}$ Nyoman Kutha Ratna, Metodologi penelitian: kajian budaya dan ilmu sosial humaniora pada umumnya (Yogyakarta: Pustaka Pelajar, 2010), 163-64.

dan realisme metaphistik, telaah studi teks dan penelitian agama (Yogyakarta: Rake Sarasin, 1996), 12. ${ }^{4}$ H. Noeng Muhadjir, Metodologi penelitian kualitatif: pendekatan positivistik, rasionalistik, phenomenologik, Jurnal Intelektual: Jurnal Pendidikan dan Studi Keislaman Volume 10, Nomor 3, Desember 2020
}

\section{Hasil Penelitian dan Pembahasan Sedulur Sikep Samin}

Dari banyak sistem pengetahuan lokal yang berkembang di Indonesia, ajaran Samin yang dipahami sebagai 'Wong Sikep' populer sebagai salah satu gerakan perlawanan terhadap kolonial. Dari sisi historis, Masyarakat Samin (Sedulur Sikep) adalah komunitas yang berasal dari ketokohan dan pemikiran atau ajaran pemimpin masyarakat yang bernama Samin Surosentiko yang lahir pada 1859 dengan nama Raden Kohar di Desa Ploso Kedhiren Randublatung Kabupaten Blora. Ia merupakan Putera dari Raden Surowijoyo.

Samin Surosentiko bernama Priyayi Raden Kohar sementara namanya yang 
Sedulur Sikep Samin: antara Pandangan dan Sistem Pengetahuan

Oleh: Hanifah Hikmawati

merakyat adalah Samin. ${ }^{5}$ Kata Samin sendiri berarti sami-sami amin. Ajaran saminisme bermula dari sebuah kegelisahan $\mathrm{R}$. Surowijoyo yang tidak tahan terhadap perilaku pemerintah Kolonial Belanda sebagai penjajah. R. Surowijoyo kemudian melakukan sebuah gerakan moral sehingga mengubah namanya menjadi Samin (Sami-sami Amin; sama rata, sama sejahtera, sama mufakat). Sebuah pemberian nama yang bernafaskan wong cilik, serta berjuluk Samin Sepuh.

Makna dari kata "Samin" ialah "samisami gesang ing alam ndonya", artinya samasama hidup di dunia. Orang hidup harus tahu hidupnya, dan mengerti serta paham hidupnya. Dalam pandangan dan ideologi orang Jawa paham hidup tersebut ialah tidak boleh bertengkar, mencuri, dengki, sombong, kepada sanak saudara dan semua manusia. Ideologi ini sebagai identitas masyarakat sedulur sikep bahwa mereka sangat memperhatikan dan menghargai sesamanya, sebagaimana yang dikatakan Harjono manusia ialah makhluk yang memperhatikan tingkah laku sendiri sekaligus merenungkan dirinya yang amat dekat dengan manusia lain. Biasa juga disebut dalam peribahasa bahasa Jawa yaitu "Kakang kawah adi ari-ari.". 6

Makna ini lantas tidak dijadikan sebagai nama penyebutan, masyarakat Samin lebih berkenan untuk dipanggil sedulur sikep oleh semua kalangan. Ini dikarenakan istilah 'sikep' bermakna 'kesadaran'. Kesadaran akan "nrima ing pandum”. Artinya, jika terdapat barang apapun yang bukan miliknya, maka tidak boleh diakui. Kesadaran inilah yang akan membangun jiwa dan pemikiran masyarakat sedulur sikep untuk menerima segala yang diberikan yang didukung oleh petuah-petuah yang kaya akan makna, seperti:

1. “Wong kudu nglakoni ngalah ananging mboten berarti kalah" (orang harus mengalah, namun bukan berarti kalah)

2. "Wong sok aja tukar padu marang pepada, merga harta mboten digawa mati" (Manusia jangan sekali-kali bertengkar terhadap sesama, karena perkara harta tidak dibawa mati)

3. "Nyawane kesasat-sasat yen mboten nanem kabecikan" (Batin tersayat-sayat jika tidak melakukan kebaikan)

4. "Ojo ngapusi lan njengkelke wongtua jaler lan wongtua wadon" (Tidak boleh berbohong dan menyakiti hati kedua orangtua)

Sedangkan itilah 'sikep' bermakna kesadaran akan "nrima ing pandum". Artinya, jika terdapat barang apapun yang bukan miliknya, maka tidak boleh diakui. Kesadaran inilah yang akan membangun jiwa dan pemikiran masyarakat Sedulur Sikep Samin untuk menerima segala yang diberikan. 
Ada singkat cerita, dahulu ada Sedulur Sanes (saudara lain yang bukan sedulur sikep) datang di tengah-tengah mereka untuk memakai Sapi. Sedulur sikep memaknai kata 'pakai' sebagai peminjaman sapi. Namun sedulur sanes memaknai 'pakai' sebagai pemberian, padahal maksud dari sedulur sikep, memakai bermakna sebagai 'meminjam'. Banyak hewan ternak dari sedulur sikep yang hilang karena salah pemaknaan. Dengan demikian, dibutuhkan interpretasi dan representasi terhadap menafsirkan simbol-simbol yang ada dalam kultur masyarakat. Konsep budaya dalam pengertian yang paling umum dan paling banyak digunakan untuk mengarahkan dan mempertimbangkan semua yang bersifat simbolik yaitu aspek-aspek ideasional dan terpelajar dalam masyarakat manusia. ${ }^{7}$

Bagi masyarakat Sedulur Sikep, yang penting dalam hidup ini adalah tabiatnya. Sekalipun seorang ulama, priyayi, beragama tetapi bertabiat tidak baik, atau buruk pekertinya. Manusia hidup yang penting bukan "lahirnya" bukan "kata-kata muluk", tetapi "isi hati” dan "perbuatan nyata". Hal demikian senada dengan yang dikatakan Baghi mengenai konsep kehidupan yang teruji hanya bertumbuh dari manusia yang sadar diri, dari mereka yang mampu mengurus diri

${ }^{7}$ Chris Jenks, Studi Kebudayaan, trans. Erika Setyawati (Yogyakarta: Pustaka Pelajar, 2013), 4.

${ }^{8}$ Felix Baghi, Redeskripsi dan Ironi : Mengolah Cita Rasa Kemanusiaan. Senayan (Nusa Tenggara Timur: dan bersedia menghargai kemanusiaan dari semua orang. Tidak peduli di mana manusia itu dilahirkan, apapun kelas sosial, gender maupun etnis, sebuah pedoman hidup yang senantiasa dijunjung tinggi adalah mengolah kemanusiaan. $^{8}$

Prinsip yang diteguhkan oleh masyarakat Sedulur Sikep dalam menghargai semua manusia tanpa terkecuali bahkan hingga zaman modernisasi saat ini. Sedulur Sikep tetap pada sifatnya yang sangat menghargai sesama manusia, bahkan hegemoni modernisasi pun turut dihargai dengan mempertimbangkan kebermanfaatan yang akan didapat. Sehingga, kehidupan Sedulur Sikep jauh mengalami perubahan. Mereka dengan tangan terbuka menerima kemajuan modernisasi sebagai bagian penting dalam kehidupan. Mereka sudah tidak mengekang diri dengan kata lain adalah membebaskan diri untuk menuju kehidupan yang dinilai lebih baik. Michel Foucault menyatakan bahwa meskipun kebebasan dihalangi, tetap akan menghasilkan resistensi dan pembangkangan. Pengetahuan berfungsi sebagai praktik kebebasan.

Hal penting lainnya yang terjadi semenjak dipimpin oleh Mbah Lasiyo adalah kesadaran memutus mata rantai sejarah karena mereka sadar tidak mungkin kembali

Ledalero, 2014), 145 , //libraria.imavi.org/index.php?p=show_detail\&id=293 7\&keywords $=$. 
Sedulur Sikep Samin: antara Pandangan dan Sistem Pengetahuan

Oleh: Hanifah Hikmawati

ke masa lampau. Seperti layaknya ahli sejarah, masyarakat Sedulur Sikep percaya bahwa sejarah tidak terjadi begitu saja (facile tendency) sebagaimana yang dikemukakan Hegelian, maka harus diperjuangkan. Benang merah sejarah baru inilah yang menjadi daya luar biasa bagi perubahan-perubahan di kalangan masyarakat Sedulur Sikep.

Adapun hal-hal baru yang didapatkan dalam penelitian ini antara lain: Pertama, terjadi kesadaran bahwa mereka kini adalah sebuah entitas budaya, bukan gerakan perlawanan seperti perjuangan pendahulu mereka. Kedua, apa yang mereka warisi dari para pendahulu sudah saatnya direorientasi, termasuk ajaran religi yang dulunya sebagai kamuflase. Religi mereka adalah sebagaimana dijalankan oleh anggota masyarakat di luar mereka. Perlahan-lahan mereka memeluk dan mempelajari agama seperti masyarakat pada umumnya. Ketiga religi kamuflase dirasa masih relevan dijalankan setelah diubah begitu rupa. Bukan agama Adam sebutannya (bahkan mayoritas anggota komunitas sudah tidak mengenal apa agama Adam), namun laku kebatinan sebagaimana orang Jawa pada umumnya.

Dalam kehidupan beragama, komunitas Samin juga mengajarkan sikap toleransi, sikap menghargai, menghormati agama dan kepercayaan orang lain. Sedulur Sikep
Samin menganggap semua agama itu baik. Komunitas Samin juga tidak membenci atau mengingkari agama, meskipun ajaran agamanya berbeda dengan ajaran agama masyarakat Klopoduwur pada umumnya. ${ }^{9}$ Mereka mengenal istilah Gusti adalah 'bagusing ati' yang merupakan ajaran kebatinan umumnya orang Jawa. Keempat, nilai-nilai baru diperkenalkan dan sosialisasinya menggunakan bahan-bahan bantu mengingat model baru seperti menuliskan di kertas ukuran besar lalu dipasang di dinding agar bisa dibaca semua orang. Hal tersebut sama sekali baru bagi mereka karena ajaran-ajaran kebatinan tidak lazim ditulis bahkan ada yang sama sekali dilarang ditulis.Kelima, hal mendasar lain yang dipraktikkan secara intens adalah kata sedulur sikep itu sendiri. Kata sikep dimaknai suatu kesadaran, kesiagaan, seperti sikep rabi. Siaga sebagai pria yang bertanggung jawab. Kesadaran tanggung jawab selanjutnya menjadi dasar perbuatan baik yang diusahakan menjadi kebiasaan baik seperti bijaksana memperlakukan alam sekitar dan nilai-nilai yang sudah dipraktikkan sejak dulu, sebagaimana "Suket, godhong, kayu, watu, kutu-kutu walang ataga kabeh sedulur. Amarga kabeh sakmenika sedulur, mula ora kena melik duweke liyan. Ora colong jupuk”. Semuanya disampaikan dalam bahasa sehari-

Indonesian Society and Culture 5, no. 1 (2013), https://doi.org/10.15294/komunitas.v5i1.2376. 
hari. Keenam, dahulu pernikahan yang terjadi di Sedulur Sikep ini harus sama-sama dengan Sedulur Sikep, karena masih terkuasa dengan sistem koloni penjajah. Namun, sekarang Sedulur Sikep Samin memperbolehkan menikah dengan jodoh yang berasal dari luar Sedulur Sikep itu sendiri, artinya menikah dengan warga yang bukan Sedulur Sikep sudah dibolehkan.

Dalam hal ini, masyarakat Sedulur Sikep masih mempercayai dan menggunakan sistem hitungan 'weton' dalam memilih jodoh. Ini merupakan bagian dari tolok ukur utama dalam hal perjodohan. Jika tidak cocok, maka bukan berarti harus memutus tali silaturahmi (medhot katresnan), karena dapat menimbulkan kesenjangan sosial. Ketujuh, setiap malam jum'at, dilakukan do'a untuk mendoakan orang tua laki-laki. Sedulur Sikep sangat ngugemi ibu. Ibu selalu mendoakan anaknya untuk menjadi anak yang saleh yang berbakti pada bangsa dan negara. Oleh karena itu, mereka sangat melarang keras membangkang dan membuat sedih hati seorang Ibu. Karena mereka percaya bahwa "sabda ibu sangat berharga." Selain itu, sedulur Sikep juga berkeyakinan atas makhluk hidup flora pohon-pohon besar yang diyakini ada yang menunggu, sebagai teman sesama yang harus dihargai. Petuah yang selalu dipegang ialah agar jangan melakukan pembantahan dari apa yang diajarkan leluhur.

\section{Asas-Asas Hidup Sedulur Sikep}

Kehidupan masyarakat Sedulur Sikep Samin memegang teguh petuah-petuah dari leluhur mereka. Terdapat nilai dan norma yang menjadi pedoman di antaranya berupa kekuatan yang mengikat bagi warganya. Konsekuensi dari semua aturan itu adalah dikucilkan oleh masyarakat Samin yang lain, bahkan dikeluarkan dari komunitas tersebut "nek memang tata cara iki dilanggar, berarti dheweke ora sedulur sikep meneh." Maksudnya jika tata cara ini ditinggalkan berarti dia bukan lagi wong sikep. ${ }^{10}$

Menurut Poso (56 tahun), anggota Sedulur Sikep yang bertindak selaku Ketua Paguyuban Tunggal Rasa, ada serangkaian nilai-nilai baru yang merupakan tuntunan baru. Nilai-nilai tersebut tidak baku dan tidak berhenti, artinya masih akan bertambah sesuai perkembangan zaman. Pada tataran tertinggi terdapat pedoman etika, "ucap, pretikel, laku."

Berikut ini adalah kutipan nilai-nilai baru tersebut. Ejaan dan tata tulisnya sesuai yang tertulis di kertas besar dan digantung di dinding pendopo.

\section{Panca Sesanti Sikep Samin}
a. Seduluran
b. Ora seneng mamungsuhan
c. Ora seneng rewang
d. Ojo ngrenah liyan
e. Eling sing kuoso

2. Panca Walika 
Sedulur Sikep Samin: antara Pandangan dan Sistem Pengetahuan

Oleh: Hanifah Hikmawati

a. Kudu trisno mring sapepada

b. Ora pareng nerak wewalering negara

c. Ora pareng sepata nyepatani

d. Ora pareng milik sing dudu samestine

e. Ora pareng cidro ing uboyo

3. Sikep Samin "Ponco Peniten"

a. Becik ketitik ala ketoro [dumunung ana ing ganda]

b. Temen bakal tinemu [dumunung ana ing pangrungu]

c. Ojo dumeh [dumunung ana ing paningal]

d. Mok mek awake dhewe [dumunung ana ing rasa]

e. Idi pesthi wek e Gusti [dumunung ana ing cipro utowo pangucap]

\section{Panca wewarer Sikep Samin}

a. Tresno pepadhane urip

b. Ora nerak wewarerane negoro

c. Ora nerak sing dudu sak mesthine

d. Ora cidra ing janji

e. Ora sepoto nyepatani

Asas-asas hidup masyarakat Sedulur

Sikep Samin merupakan kebenaran yang dikonvensikan menjadi ideologi. Ideologi ini menandakan adanya keputusan mutlak dan kolektif dari suatu komunitas dalam melangsungkan hidup atas dasar asas. Hal demikian sebagaimana yang dikemukakan oleh Snijders bahwa manusia itu tetap dalam perjalanan "menuju kebenaran" yang bersifat paradoksal, dinamis, dan multidimensional. ${ }^{11}$
Dengan demikian, dapat dikatakan bahwa kelompok masyarakat adalah prinsipprinsip langsung atau kausa-kausa efektif dari perbuatan afektif. Semua dinamisme afektif yang terkumpul dalam suatu subjek tertentu merupakan suatu kesatuan, suatu keseluruhan yang difinalisasikan dan dihirarkikan. Betapapun juga jumlah kecenderungankecenderungan dan selera-selera yang memungkinkan suatu subjek berkembang, betapapun juga banyaknya jenis dari hal baik yang mereka inginkan, pada akhirnya selalu kemantapan dan kemajuan dari "adanya" sendirilah yang dicari dan dikejar. ${ }^{12}$

Masyarakat Sedulur Sikep sangat patuh terhadap asas-asas tersebut sebagai pedoman hidup menuju kebenaran afektif. Kebenaran yang didasarkan pula atas asas idealisme. Idealisme dari asas-asas panca sesanti, panca walika, ponco peniten, dan panca wewarer sebagai usaha menuju manusia hakiki yang dipandang sebagai sesuatu yang ada pada masa sekarang dan masa depan yang selalu menarik manusia untuk melakukannya dan mewujudkannya. Sebagaimana Borgias mengatakan bahwa idealisme merupakan suatu dinamika masa depan yang menarik dan menggerakkan salah satu aspek dalam diri manusia pada saat sekarang dan di sini, yaitu aspek kemauan (kehendak) untuk terus mengembangkan diri.
11 Sneijdrs Adelberrt, Manusia Dan Kebenaran Sebuah Filsafat Pengetahuan (Yogyakarta: Kanisius, 2010), 35.
12 Louis Leahy, Manusia, sebuah misteri: sintesa filosofis tentang makhluk paradoksal (Jakarta: Gramedia, 1984), 97. 
Dalam keadaan demikian, wajar jika manusia mempunyai idealisme sebagaimana masyarakat Sedulur Sikep sebagai tonggak yang mau dicapai dalam proses "berkembang" tersebut. ${ }^{13}$

\section{Perihal Pengetahuan}

Nilai-nilai baru dan keyakinankeyakinan baru selanjutnya menjadi materi pengajaran bagi generasi muda dan anggota komunitas lainnya. Pengetahuan sebagai bekal menjalani kehidupan sehari-hari juga diajarkan sejak usia anak-anak hingga dewasa. Anak-anak bersekolah dan bermain seperti anak-anak pada umumnya. Para remaja sebagian meneruskan pendidikan formal lebih tinggi dan sebagian lagi bekerja di kota.

\section{a. Pendopo}

Gelombang kesadaran baru di kalangan masyarakat Sedulur Sikep ditandai dengan pendirian bangunan Pendopo. Pendopo yang didirikan tahun 2010 ini tidak terdapat di komunitas Sedulur Sikep mana pun dan tidak terbayangkan sebelumnya. Landasannya adalah kesadaran ruang bagi terbentuknya praktik kebebasan. Namun pendirian pendopo saja tidak cukup. Tersedianya ruang harus sejalan dengan jiwa kebebasan di antara semua anggota. Dengan begitu ruangan tersebut dapat berfungsi sebagaimana mestinya dengan berlatih bertemu muka di ruangan pendopo bagi para anggota dapat mulai menemukan jati dirinya sendiri.

Mereka mulai diperkenalkan tentang laku-laku kebatinan seperti puasa hari kelahiran, berpantang garam (mutih), makan hanya dari umbi-umbian (ngrowot) dan seterusnya, yang intinya mulai belajar kepekaan rasa bergaul dengan alam sekitar. Orang-orang dewasa mempelajari kebatinan dalam berbagai tahap dan metode. Namun ilmu tertentu hanya diajarkan kepada keturunan langsung Mbah Lasiyo misalnya rincian sesajen dan cara mendoakan. Semuanya mengarah kepada pengetahuan empirik (laku) sejak berucap (jawab) kepada alam sekitarnya hingga memecahkan masalah berdasarkan ide kreatif (pertikel). Pengajaran ilmu kebatinan terutama diajarkan di Pendopo.

\section{b. Sarasehan}

Sarasehan dilakukan tiap hari Selasa Kliwon. Kegiatan ini dilakukan dengan berkumpul dan membahas pelajaran dan diskusi dan menjadi tempat yang takzim bagi uraian pedoman laku bagi anggota komunitas.

Dalam sarasehan dibicarakan semua hal mulai uraian laku kebatinan hingga pengetahuan hidup sehari-hari lainnya. Sementara para bapak berkumpul sarasehan

13 Fransiskus Borqias M, Manusia pengembara: refleksi filosofis tentang manusia (Yogyakarta: Jalasutra, 2013), 59. 
Sedulur Sikep Samin: antara Pandangan dan Sistem Pengetahuan

Oleh: Hanifah Hikmawati

dan para ibu berkumpul untuk "Dadi manungsa ora kena drengki, srei, mengembangkan aktifitas membatik. dahwen, panasten" yang merupakan penyakit Semuanya berguna untuk transfer hati. Begitu juga tidak boleh mencuri bahkan pengetahuan menuju hidup yang lebih baik.

c. Sistem Penamaan

tidak boleh menginginkan memiliki barang

Sistem penamaan pada masyarakat sedulur sikep sudah sangat maju. Artinya, penamaan masa lalu sudah jarang digunakan. Misal penamaan masa sekarang ini ialah Dwi Setyawan, Fitri Kusrini, Catur Setyawan, dan seterusnya.

d. Udeng yang bukan haknya.

e. Pekerjaan

Mayoritas sedulur sikep semua bekerja. Kaum matriarkal (perempuan) diizinkan untuk bekerja pula dan diizinkan bekerja di luar rumah.

\section{f. Kelompok Tani}

Pendirian kelompok tani berlandaskan

Udeng adalah kain yang diikat di kepala. Makna filosofis dari udeng berasal dari kosa kata bahasa Jawa 'mudheng', yang mana manusia diharapkan agar mudheng (paham) untuk saling menyatu, dan guyup rukun. Identitas fisik yang tetap dipertahankan adalah busana terdiri atas ikat kepala wulung, baju koko warna hitam, dan celana pangsi warna hitam di bawah lutut. Ikat kepala sebagai lambang pengendalian pikiran dan fokus. Ikat kepala juga disebut udheng, merupakan sanepan untuk mudheng atau paham atau cerdas. Motifnya biasanya cemukiran calacap modhang yaitu motif menyerupai paruh burung kepodang. Kepodhang mas (berparuh keemasan) dalam masyarakat Jawa merupakan lambang ujar manis atau kata-kata bijak. Warna hitam merupakan benda pembantu pengingat bahwa manusia harus selalu berusaha hidup dengan bersih baik dalam pikiran maupun perbuatan. atas kesadaran akan pentingnya meningkatkan penghasilan mereka karena mayoritas anggota Sedulur Sikep berprofesi sebagai petani. Mereka merasa perlu meningkatkan pengetahuan tentang pertanian. Orientasinya juga sama seperti masyarakat lain. Dulu pola pertanian mereka adalah subsistem di mana hasil pertanian tidak dijual melainkan untuk mencukupi kebutuhan makan sehari-hari. Namun melihat hasil pertanian yang makin baik maka orientasi hasil pertanian adalah industri. Sebagian besar jual dan sebagian lagi dimakan sendiri. Begitu juga tanaman sela seperti sayuran dan buah-buhan sebagian kecil dijual dan sebagian besar dimakan sendiri. Dengan oerientasi seperti ini jelas mereka sangat terbuka terhadap masuknya teknologi pertanian.

\section{g. Bersih Desa}

Bersih desa diadakan setiap pada bulan setelah syawal (dzulqo'dah). 


\section{h. Taman Bacaan Masyarakat (TBM)}

TBM ini baru saja dibangun seperti rumah desa untuk kegiatan belajar bersama. Pengetahuan untuk anak-anak diajarkan di sekolah dan di rumah, ditambah memperkaya pengetahuan di TBM. Para remaja mulai belajar ilmu kebatinan dalam taraf tertentu.

\section{i. Alegori (simbol-menyimbol)}

Semua benda dianggap sebagai simbol, baik simbol verbal maupun tulisan. Kemudian ada bahan yang ditransmisikan sebagai proses transformasi masyarakat baru. Misalnya 'abang' sebagai tanda kemarahan dan 'klomot' sebagai tanda manusia itu abuabu atau mempunyai banyak dosa.

\section{j. Sesaji}

Sesaji yang paling dianggap tinggi ialah jambe, suruh, kembang wangi pancawarna yang statusnya tidak boleh diganggu gugat. Jambe dilambangkan sebagai lambe/ucapan, suruh sebagai ruh/jiwa, kembang wangi sebagai menyambungkan hidup bersama. Sedangkan untuk doa, diucapkan secara niat hati dan tidak harus diucapkan secara lisan.

Sesaji ketika mendirikan rumah berupa klopo, padi, dan tebu. Masyarakat sedulur sikep tidak menggunakan susuk paku emas untuk mendirikan rumah seperti di tempat lain. Sedulur Sikep melakukan dan membuat sajen hanya ketika ada agenda 7 bulanan kehamilan yang dalam bahasa Jawa dinamakan 'mitoni'. Sajen tersebut terdiri dari kereweng, welat, kunir, opeh, uplik, sapu sada, benang. Kemudian setelah lahir, ari-ari dianggap sebagai pusaka, khususnya bagi sang bayi. Oleh karena itu, harus dirawat sebaik mungkin.

Banyak kesempatan yang bisa dipakai sebagai media pembelajaran. Setiap acara besar tertentu selalu disediakan sekurangkurangnya 5 jenis jenang:

1. Jenang abang, terdiri dari beras, gula Jawa

2. Jenang putih, terdiri dari beras dan santan

3. Jenang abang putih, terdiri dari beras, beras biasa dan gula Jawa

4. Klomot, terdiri dari jenang ketan hitam, santan, dan kelapa

5. Arang-arang kambang, terdiri dari ketan hitam dan santan

Semuanya melambangkan kesuburan dan pengendalian hawa nafsu menuju hidup yang bersih untuk selalu ingat kepada sang pencipta. Keempat jenang dan cara meletakkan juga merupakan ajaran. Jenang putih di sebelah timur, jenang klomotan di sebelah selatan, jenang arang-arang kambang di sebelah barat, jenang abang di sebelah utara, dan jenang abang putih di tengahtengah. Kiblat papat lima pancer itulah bunyi ajaran spasial.

Sajen lain yang penting adalah saat mengubur ari-ari bayi yang baru lahir. Ada 7 rupa benda simbol doa yaitu: kereweng (pecahan genting lambang pengayoman), welat (pemotong tali pusat yang 
Sedulur Sikep Samin: antara Pandangan dan Sistem Pengetahuan

Oleh: Hanifah Hikmawati

melambangkan penderitaan dan ketajaman pikir), kunir (lambang kesehatan, seger waras), opeh (pelepah pohon pinang atau jambe lambang alat ucap manusia), uplik (dian berbahan bakar minyak lambang jalan terang) yang dinyalakan tanpa dimatikan selama 35 hari, sapu lidi (lambang kebersihan hati), benang (lambang ikatan persaudaraan). Ari-ari (placenta) dianggap sebagai pusaka karena saudara kandung si bayi (adhi ari-ari), maka harus dirawat sebaik mungkin.

Rangkaian sesaji dalam upacara adat masyarakat Sedulur Sikep cukup banyak, namun terdapat beberapa benda yang selalu ada. Sesaji yang harus ada di setiap rangkaian acara atau peristiwa yang memerlukan sajen adalah jambe (pinang), sirih, dan kembang wangi. Bagian yang diambil dari pohon jambe adalah pelepah atau buahnya. Jambe diambil suku kata terakhir yaitu 'mbe' sebagai sanepan untuk 'lambe' (bibir manusia) sebagai simbol agar manusia dapat memanfaatkan dan menjaga ucapan sebagai jendela hubungan manusia dengan tuhan, dengan sesama manusia, dan dengan alam sekitarnya. Tanaman sirih yang diambil hanya bagian daunnya. Sirih dalam bahasa Jawa disebut suruh, diambil suku kata terakhir 'ruh', untuk memuliakan ruh manusia sebagai penjaga kehidupan. Adapun kembang wangi sebagai lambang martabat manusia dalam

\section{Kesimpulan}

Penelitian ini memaparkan sistem pengetahuan masyarakat Sedulur Sikep Samin Blora yang menjadi identitas dan simbol dari masyarakat itu sendiri sebagai masyarakat yang berbasis pengetahuan dan perjalanan “menuju kebenaran" yang bersifat paradoksal, dinamis, dan multidimensional. Ajaran-ajaran dan sistem pengetahuan yang berkembang di masyarakat Sedulur Sikep Samin merupakan bagian dari kearifan lokal yang menjadi ideologi dan pembelajaran atas resolusi efektif bagi kurun zaman dan masa ke masa.

Sistem pengetahuan yang telah melalui perubahan, khususnya dalam hegemoni modernitas yang menjadikan masyarakat Sedulur Sikep membuka tangan untuk menerima perkembangan modernitas tersebut dengan menimbang kebermanfaatan yang didapatkan, khususnya dalam kelangsungan hidup sehari-hari. Nilai-nilai dan keyakinan-keyakinan pada sistem pengetahuan selanjutnya menjadi materi pengajaran bagi generasi muda dan anggota komunitas lainnya. Selain itu pengetahuan sebagai bekal menjalani kehidupan sehari-hari diajarkan sejak usia dini hingga dewasa sebagai regenerasi.

\section{Daftar Pustaka}

Abdullah, Irwan. Konstruksi dan reproduksi kebudayaan. Yogyakarta: Pustaka Pelajar, 2006. 
Adelberrt, Sneijdrs. Manusia Dan Kebenaran - Sebuah Filsafat Pengetahuan. Yogyakarta: Kanisius, 2010.

Baghi, Felix. Redeskripsi dan Ironi: Mengolah Cita Rasa Kemanusiaan. | Senayan. Nusa Tenggara Timur: Ledalero, 2014. //libraria.imavi.org/index.php?p=sho w_detail\&id=2937\&keywords=.

Harjono, KH Amin Maulana Budi. Menjelajahi Kearifan Cinta: Diandra Kreatif. Diandra Pustaka Indonesia, 2014.

Jenks, Chris. Studi Kebudayaan. Translated by Erika Setyawati. Yogyakarta: Pustaka Pelajar, 2013.

Leahy, Louis. Manusia, sebuah misteri: sintesa filosofis tentang makhluk paradoksal. Jakarta: Gramedia, 1984.

Lestari, Indah Puji. "INTERAKSI SOSIAL KOMUNITAS SAMIN DENGAN MASYARAKAT SEKITAR." KOMUNITAS: International Journal of Indonesian Society and Culture 5, no. 1 (2013). https://doi.org/10.15294/komunitas.v 5i1.2376.

M, Fransiskus Borqias. Manusia pengembara: refleksi filosofis tentang manusia. Yogyakarta: Jalasutra, 2013.

Muhadjir, H. Noeng. Metodologi penelitian kualitatif: pendekatan positivistik, rasionalistik, phenomenologik, dan realisme metaphistik, telaah studi teks dan penelitian agama. Yogyakarta: Rake Sarasin, 1996.

Purwasito, Andrik. Komunikasi multikultural. Surakarta: Universitas Muhammadiyah Surakarta, 2003.

Ratna, Nyoman Kutha. Metodologi penelitian: kajian budaya dan ilmu sosial humaniora pada umumnya. Yogyakarta: Pustaka Pelajar, 2010.

Wibowo, Y. "Sastra Dan Peta Yang (Tak) Usai Terbaca." Accessed November
29, $2020 . \quad$ http://sastraindonesia.com/2008/08/sastra-danpeta-yang-tak-usai-terbaca/. 